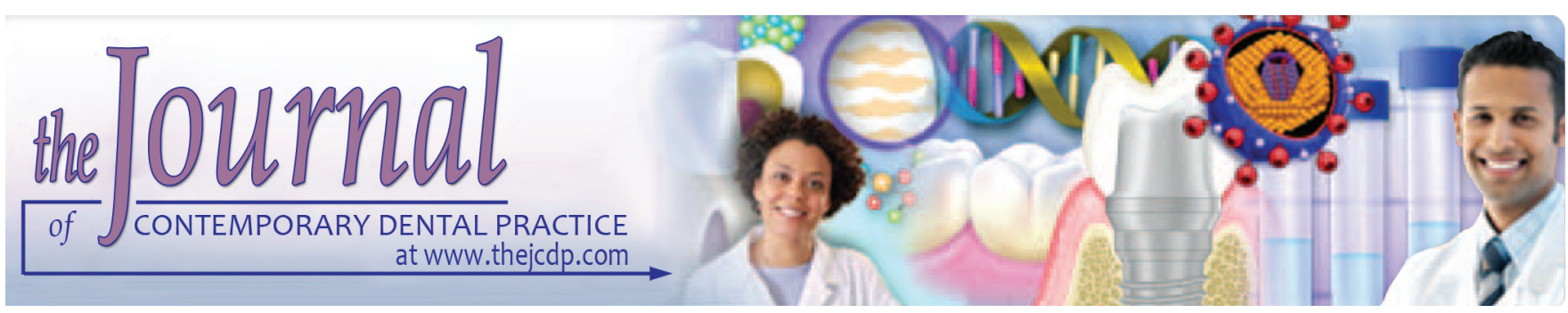

\title{
Crestal Bone Loss around Dental Implants: Platform Switching vs Platform Matching-A Retrospective Study
}

\author{
${ }^{1}$ Rashmita Nayak, ${ }^{2}$ Raghu Devanna, ${ }^{3}$ Anand M Dharamsi, ${ }^{4}$ Jeevan Shetty, ${ }^{5}$ Rizwan Mokashi, ${ }^{6}$ Sourav Malhotra
}

\section{ABSTRACT}

Aim: The objective of this study was to determine the vertical and horizontal marginal bone levels in platform-switched and platform-matched dental implants.

Materials and methods: In the present study, 50 dental implants were placed in 50 patients over a 1-year period. Measurement was performed from the implant shoulder to the most apical and horizontal marginal defect by periapical radiographs to examine the changes of peri-implant alveolar bone before and 12 months after prosthodontic restoration delivery.

Results: These marginal bone measurements showed a bone gain of $0.53 \pm 0.98 \mathrm{~mm}$ in the vertical gap and $0.52 \pm 0.93 \mathrm{~mm}$ in the horizontal gap of the platform matching, while in the platform switching, a bone gain of $1.33 \pm 1 \mathrm{~mm}$ in the vertical gap $(p<0.05)$ and $1.60 \pm 0.56 \mathrm{~mm}$ in the horizontal gap was found. Statistically significant difference was found for bone regeneration in the vertical gap between the two groups $(p<0.05)$ using t-test with Statistical Package for the Social Sciences (SPSS) statistical test version 17 .

\footnotetext{
${ }^{1}$ Department of Periodontology \& Oral Implantology, Institute of Dental Sciences, Siksha 'O' Anusandhan (Deemed to be University), Bhubaneswar, Odisha, India

${ }^{2}$ Orthodontic Division, Department of Preventive Dentistry Faculty of Dentistry, Taif University, Al-Taif, Kingdom of Saudi Arabia

${ }^{3}$ Department of Periodontology, R.R. Dental College \& Hospital Udaipur, Rajasthan, India

${ }^{4}$ Department of Periodontology, Dr. Shetty's Dental Specialities Bengaluru, Karnataka, India

${ }^{5}$ Department of Conservative Dentistry \& Endodontics \& Aesthetic Dentistry, S.M.B.T. Dental College \& Hospital, Nashik Maharashtra, India

${ }^{6}$ Department of Oral Medicine, D.A.V. Dental College, Solan Himachal Pradesh, India

Corresponding Author: Rashmita Nayak, Department of Periodontology \& Oral Implantology, Institute of Dental Sciences, Siksha 'O' Anusandhan (Deemed to be University) Bhubaneswar, Odisha, India, e-mail: rashmitanayak@ souniversity.ac.in
}

Conclusion: The crestal bone around the implants can be preserved with platform-switching concept and it can be applied in clinical condition.

Clinical significance: The crestal bone around the implants can be preserved with platform-switching concept.

Keywords: Crestal bone, Dental implants, Platform switching.

How to cite this article: Nayak R, Devanna R, Dharamsi AM, Shetty J, Mokashi R, Malhotra S. Crestal Bone Loss around Dental Implants: Platform Switching vs Platform Matching-A Retrospective Study. J Contemp Dent Pract 2018;19(5):574-578.

Source of support: Nil

Conflict of interest: None

\section{INTRODUCTION}

The presence of sufficient amount of bone and its quality, especially crestal bone around implant, can predict the successful outcome of dental implant. However, bone loss at the peri-implant site is quite common. Adell et $\mathrm{al}^{1}$ evaluated the marginal bone loss at the initial period of prosthetic loading.

Implant failure is secondary to peri-implantitis and bone loss due to the initial crestal bone loss and bacterial invasion. This, in turn, results into occlusal overload. The loss of interproximal papilla could be due to loss of marginal bone and gingival contour. ${ }^{2}$

Abrahamsson et $\mathrm{al}^{3}$ observed a 1.5 to $2.0 \mathrm{~mm}$ of crestal bone loss after 1 year of loading and after installation of a two-piece healing implant in a submerged modality. However, $2 \mathrm{~mm}$ of crestal bone remodeling resorption was observed in an experimental study in dogs. Hence, research is going on to reduce the crestal bone loss.

A bone loss of approximately $2 \mathrm{~mm}$ around the implant during the first year of implant placement is acceptable and considered as successful in Toronto Conference. ${ }^{4}$ Various reported studies highlighted the causes for bone loss around implant and clinical methods to prevent 
it. Platform-switching technique is one such method in which an abutment that is one size smaller than the implant platform is placed to prevent bone loss around the implant. 5,6 Such a connection shifts the perimeter of the implant-abutment junction (IAJ) inwardly toward the central axis of the implant. The crestal bone loss can be reduced by repositioning the outer edge of the implant abutment interface horizontally inward and away from the outer edge of the implant platform.

Therefore, crestal bone preservation should be planned before the placement of the implant. Various methods are suggested to reduce crestal bone loss, such as platform-switching technique. The aim of the present study was to observe the changes in both vertical and horizontal marginal bone defects measured between the implant shoulder and the most apical and horizontal marginal defect by using periapical radiographs to examine the changes in mesial and distal peri-implant alveolar bone before and 12 months after prosthodontic restoration delivery between platform-switched and platform-matched dental implants.

\section{MATERIALS AND METHODS}

The study was conducted on 50 healthy individuals with an age group of 25 to 60 years who require single implant replacement. Informed consent was obtained from all the participating subjects and institutional ethical consent was obtained before start of the study. XiVE implants were placed within 6 weeks after tooth extraction. The full thickness mucoperiosteal flap was elevated by giving local anesthesia and a midcrestal incision in the edentulous area. Dental implants were placed and flaps were sutured. Subjects received postoperative instructions and were advised to rinse with chlorhexidine $0.12 \%$ twice a day for 10 days, and sutures were removed 2 weeks thereafter. All implants were inserted until the outer edge of the dental implant reached the marginal bone level, to allow for the apex of the cover screw to be at level with the bone crest during the healing period. Surgical and prosthetic restoration procedures were performed by the same trained dental surgeon in a total of 50 patients between 2011 and 2016. After 3 months of implant insertion, a second-stage surgery was carried out and the healing abutments were placed in all the individuals.

Implant level impressions were taken 2 weeks postoperatively to the healing abutment surgery connection. The permanent metal ceramic crown was delivered 2 weeks after impressions. Overall, 25 patients received 30 platform-matched dental implants (diameter: 3.0$4.5 \mathrm{~mm}$; length: $10-13 \mathrm{~mm}$ ); on the contrary, 25 patients received 30 platform-switched dental implants (diameter: 3.0-4.8 mm; length: 10-12 mm). Both groups were followed up for 12 months after the final prosthetic restoration was delivered. Digital periapical radiographs of the dental implants were recorded at different time points: before loading (baseline); immediately after loading; and 1, 3, 6, and 12 months after loading. The implant shoulder was considered as the reference point for measuring vertical and horizontal dimensions (vertical bone gap and horizontal bone gap) of the mesial and distal peri-implant marginal bone defect; the same measurements were used to evaluate bone remodeling through the 12 months of follow-up.

The data are presented as means \pm standard error and were analyzed by SPSS version 17 at a significance level of $\mathrm{p} \leq 0.05$. Independent and paired sample t-tests were conducted and comparisons were computed by means with repeated measures within and between groups respectively. The statistical evaluation of the difference in mesial and distal marginal bone gap loss was accomplished with independent t-test.

\section{Inclusion Criteria}

- Nonsmoking or smoking history of $<6$ cigarettes per day.

- Good oral hygiene with full-mouth plaque score $\leq 25 \%$ at baseline; full-mouth bleeding on probing $\leq 25 \%$ at baseline; probing depth of pocket adjacent to the implant site in six aspects of the teeth $\leq 3 \mathrm{~mm}$.

- Periodontal attachment level adjacent to the implant site at six aspects of the teeth $\leq 2 \mathrm{~mm}$.

- No periapical lesions.

\section{Exclusion Criteria}

The exclusion criteria were as follows: patients with any local or systemic disease, smoking more than 6 cigarettes / day, betel nut or tobacco chewing, alcoholism, pregnancy or breastfeeding, long-term oral medications, oral parafunction, nontreated periodontal disease, and inadequate bone volume.

\section{RESULTS}

There was no statistically significant difference for demographic data between the groups. In total, 50 patients (25 men and 25 women) received 50 dental implants in the present study. Overall, 25 platform-matched implants were implanted in a total of 25 patients (mean age: 43.8 \pm 20.7 and $44.1 \pm 24$ years). On the contrary, 25 platformswitched implants were placed in 25 patients (mean age: $43.1 \pm 28$ and $42.3 \pm 16.7$ years $)$.

Table 1 indicates vertical bone gap variations from platform-switched implants. The mean vertical bone gap in platform-switched implants was $3.06 \pm 1.11 \mathrm{~mm}$ before loading; $3.12 \pm 1.01 \mathrm{~mm}$ mean immediately after loading; 
Table 1: Platform switching (mean $\pm \mathrm{SD}, \mathrm{mm}$ )

\begin{tabular}{lllllll}
\hline & Mesial (vertical) & Distal (vertical) & Mean $(\mathrm{mm})$ & Mesial (horizontal) & Distal (horizontal) & Mean (mm) \\
\hline Baseline & $3.01 \pm 1.3$ & $3.11 \pm 1.39$ & $3.06 \pm 1.11$ & $2.61 \pm 1.41$ & $2.30 \pm 1.02$ & $2.46 \pm 1.22$ \\
Immediately after loading & $3.12 \pm 1.2$ & $3.12 \pm 1.21$ & $3.12 \pm 1.01$ & $2.81 \pm 1.42$ & $2.31 \pm 1.11$ & $2.56 \pm 1.31$ \\
1 month after loading & $2.95 \pm 1.3$ & $3.13 \pm 1.31$ & $3.04 \pm 1.21$ & $2.91 \pm 1.31$ & $2.01 \pm 0.91$ & $2.46 \pm 1.12$ \\
3 months after loading & $2.81 \pm 1.28$ & $2.91 \pm 1.50$ & $2.86 \pm 1.30$ & $2.61 \pm 1.30$ & $1.90 \pm 0.81$ & $2.26 \pm 1.23$ \\
6 months after loading & $2.39 \pm 1.21$ & $2.4 \pm 1.01$ & $2.4 \pm 0.94$ & $2.8 \pm 1.11$ & $1.63 \pm 0.71$ & $2.22 \pm 0.90$ \\
12 months after loading & $2.01 \pm 1.01$ & $2.31 \pm 1.21$ & $2.16 \pm 1.02$ & $2.71 \pm 1.01$ & $1.83 \pm 1.0$ & $2.27 \pm 0.91$ \\
\hline
\end{tabular}

Test used: t-test significance: $p<0.05$; SD: Standard deviation

Table 2: Platform matching (mean $\pm \mathrm{SD}, \mathrm{mm}$ )

\begin{tabular}{lllllll}
\hline & Mesial (vertical) & Distal (vertical) & Mean $(\mathrm{mm})$ & Mesial (horizontal) & Distal (horizontal) & Mean $(\mathrm{mm})$ \\
\hline Baseline & $2.1 \pm 1.3$ & $2.43 \pm 1.05$ & $2.26 \pm 1.1$ & $2.36 \pm 1.2$ & $2.30 \pm 1.01$ & $2.33 \pm 0.97$ \\
Immediately after loading & $2.12 \pm 1.0$ & $2.22 \pm 0.95$ & $2.17 \pm 0.84$ & $2.53 \pm 1.3$ & $2.2 \pm 1.03$ & $2.37 \pm 1.2$ \\
1 month after loading & $2.0 \pm 0.98$ & $2.23 \pm 0.96$ & $2.12 \pm 0.90$ & $2.55 \pm 1.2$ & $2.1 \pm 1.0$ & $2.33 \pm 1.0$ \\
3 months after loading & $2.04 \pm 1.3$ & $2.14 \pm 0.9$ & $4.18 \pm 0.85$ & $2.54 \pm 1.3$ & $2.2 \pm 1.1$ & $2.37 \pm 1.1$ \\
6 months after loading & $2.0 \pm 1.4$ & $2.12 \pm 1.1$ & $2.06 \pm 1.12$ & $2.5 \pm 1.05$ & $1.96 \pm 1.0$ & $2.23 \pm 0.99$ \\
12 months after loading & $2.08 \pm 0.99$ & $1.01 \pm 0.95$ & $1.55 \pm 0.82$ & $2.37 \pm 0.95$ & $1.95 \pm 0.83$ & $2.16 \pm 0.77$ \\
\hline
\end{tabular}

Test used: t-test significance: $p<0.05$; SD: Standard deviation

$3.04 \pm 1.21 \mathrm{~mm}$ mean 1 month after loading; $2.86 \pm 1.30 \mathrm{~mm}$ mean 3 months after loading; $2.4 \pm 0.94 \mathrm{~mm}$ mean 6 months after loading; and $2.16 \pm 1.02 \mathrm{~mm}$ mean 12 months after loading. Statistical analysis showed a statistically significant difference $(\mathrm{p}<0.05)$ between the baseline and 6 months, and between the baseline and 12 months in all the vertical measurements (Table 1).

Horizontal bone gap variations in platform-switched implants are shown in Table 1. The mean horizontal bone gap in platform-switched implants was $2.46 \pm 1.22 \mathrm{~mm}$ mean before loading; $2.56 \pm 1.31 \mathrm{~mm}$ mean immediately after loading; $2.46 \pm 1.12 \mathrm{~mm}$ mean 1 month after loading; $2.26 \pm 1.23$ mm mean 3 months after loading; $2.22 \pm 0.90 \mathrm{~mm}$ mean 6 months after loading; and $2.27 \pm 0.91 \mathrm{~mm}$ mean 12 months after loading. Statistical analysis showed a statistically significant difference $(p<0.05)$ between the baseline and 6 months, and between the baseline and 12 months in all the horizontal measurements (Table 1).

Table 2 indicates the vertical marginal bone gap variations in platform-matched implants during the 12-month study period. The mean vertical bone gap in platformmatched implants was $2.26 \pm 1.1 \mathrm{~mm}$ before loading; 2.17 $\pm 0.84 \mathrm{~mm}$ mean immediately after loading; $2.12 \pm 0.90$ $\mathrm{mm}$ mean 1 month after loading; $4.18 \pm 0.85 \mathrm{~mm}$ mean 3 months after loading; $2.06 \pm 1.12 \mathrm{~mm}$ mean 6 months after loading; and $1.55 \pm 0.82 \mathrm{~mm}$ mean 12 months after loading. There was a statistically significant finding $(p<0.05)$ between the baseline and 12 months in distal measurements (Table 2).

The horizontal bone gap results in platform-matched implants are shown in Table 2. The mean horizontal bone gap in platform-matched implants was $2.33 \pm 0.97 \mathrm{~mm}$ mean before loading; $2.37 \pm 1.2 \mathrm{~mm}$ mean immediately after loading; $2.33 \pm 1.0 \mathrm{~mm}$ mean 1 month after loading;
$2.37 \pm 1.1 \mathrm{~mm}$ mean 3 months after loading; $2.23 \pm 0.99 \mathrm{~mm}$ mean 6 months after loading; and $2.16 \pm 0.77 \mathrm{~mm}$ mean 12 months after loading. Statistical analysis showed no statistically significant differences between the baseline and the rest of the time points in any of the horizontal measurements (Table 2).

These marginal bone measurements showed a bone gain of $0.53 \pm 0.98 \mathrm{~mm}$ in the vertical gap and $0.52 \pm$ $0.93 \mathrm{~mm}$ in the horizontal gap of the platform matching, while in the platform switching, a bone gain of $1.33 \pm$ $1 \mathrm{~mm}$ in the vertical gap $(\mathrm{p}<0.05)$ and $1.60 \pm 0.56 \mathrm{~mm}$ in the horizontal gap was found. Only a statistically significant difference was found comparing bone gains in the vertical gap between the two groups $(\mathrm{p}<0.05)$.

\section{DISCUSSION}

During the 1-year study period in the present study, there was lesser marginal bone loss observed in platformswitching concept compared with abatement diameter of the matching bone implant.

From the available literature, it has been confirmed that crestal bone resorption can be reduced with a major contributing factor, such as platform-switching method. Biological width is important in maintaining the soft and hard tissues. The IAJ is shifted inwardly in the platformswitching technique. This makes the inward shift of the inflammatory infiltrate away from the crestal bone and creates a horizontal biologic width and hence preserves the crestal bone. At the same time, it decreases the chance of bone resorption by shifting of the micro-gap away from the crestal bone. ${ }^{7}$

The etiology of bone remodeling was believed to be dependent on the localized inflammation of the periimplant soft tissue. ${ }^{8}$ This is supported, especially at the 
IAJ for micro-gap, and the abutment site was infiltrated by inflammatory cells, where it is always possible to detect bacterial infiltration, as reported by Jansen et al. ${ }^{9}$

In the present study, both platform-switched and platform-matched implant groups exhibited reduced vertical and horizontal gaps at the end of 12 months. There was a greater reduction in the mean marginal bone gaps in the platform-switched dental implants, with only statistically significant differences between the two groups at the end of 12 months in the vertical measurements, where the platform-switched implants presented more mean reduction in the vertical marginal bone gap $(2.16 \pm 1.02 \mathrm{~mm})$ than the platform-matched implants did $(1.55 \pm 0.82 \mathrm{~mm})$. Similar results have been reported in previous studies, with a better marginal bone level in platform-switched implants. ${ }^{10,11}$ In addition, the platform-switching concept helps to obtain satisfactory long-term esthetic results by the mean marginal bone reduction obtained in vertical and horizontal gaps. ${ }^{12,13}$

A recent systematic review and meta-analysis study with a total of 26 studies involving 1,511 platformswitched implants and 1,123 platform-matched implants indicated that platform switching within 18 months following crown placement had a lower vertical marginal bone loss $(0.23 \mathrm{~mm})$ compared with platform-matched implants. After more than 1 year of function, slight soft tissue loss was observed in platform-switched implants; hence, the results of soft tissue should be interpreted with caution for a better long-term successful treatment. The authors concluded that platform switching may have an indirect protective effect on implant hard tissue outcomes. $^{14}$

The platform-switching concept is a recent approach that aims to reduce or control the bone loss at the horizontal component; it refers to the use of a smaller diameter abutment on a larger diameter implant platform. Such a connection shifts the perimeter of the IAJ inwardly toward the central axis of the implant to preserve the marginal bone from stress concentration. It is also believed that crestal bone resorption can be reduced by inflammatory cell infiltration to long axis of implant and away from the crestal bone site and with an inward movement of IAJ. Moreover, crestal bone loss and soft tissue stability are influenced by the abutment collar length which controls the final crown margin location and the subsequent esthetic outcome. ${ }^{6,15}$

All studies comparing the implants for platformswitching and nonswitching type suggested that implant for platform-switched type showed a lower resorption rate for marginal bone. Hürzeler et $\mathrm{al}^{16}$ compared the loss of crestal bone around implants for platform-switched and nonplatform-switched type. There was $0.22 \mathrm{~mm}$ of mean crestal bone loss in platform-switched implants and nonplatform-switched implants, which was $2.02 \mathrm{~mm}$. They also found that a $0.45 \mathrm{~mm}$ abutment reduction on either side is sufficient to avoid peri-implant bone loss. Another study by Cappiello et $\mathrm{al}^{17}$ found that the vertical bone loss for the platform-switched cases varied between 0.6 and $1.2 \mathrm{~mm}$ (mean: $0.95 \pm 0.32 \mathrm{~mm}$ ), while for the cases without platform switching, there was an average of 1.3 and $2.1 \mathrm{~mm}$ (mean: $1.67 \pm 0.37 \mathrm{~mm}$ ) of bone loss. In nonplatform-switched implants, 1 to $2 \mathrm{~mm}$ average of bone loss occurred, whereas there was minimal bone loss found in platform-switched implants.

Implant-abutment interface is a very important criterion for implant success.

Platform switching increases the distance between IAJ and the crestal bone, thereby increasing the micro-gap to crestal bone distance, hence preserving the crestal bone, but it does not affect the width of the micro-gap. The precision fit of implant-abutment connection in Morse taper or internal hex implants offer an additional advantage of reduced micro-gap. So, the introduction of combination of Morse taper connection and platform switching can be a boon to implant dentistry.

\section{CONCLUSION}

The concept of crestal bone loss around the implant plays an important role for the overall success rate. Platform switching helps to prevent the bone loss around the implants and thus this concept must be used in clinical practice.

\section{REFERENCES}

1. Adell R, Lekholm U, Rockler B, Branemark PI. A 5 year study of osseointegrated implants in the treatment of edentulous jaw. Int J Oral Surg 1981 Dec;10(6):387-416.

2. Tarnow DP, Magner AW, Fletcher P. The effect of the distance from the contact point to the crest of bone on the presence or absence of the interproximal dental papilla. J Periodontol 1992 Dec;63(12):995-996.

3. Abrahamsson I, Berglundh T, Wennström J, Lindhe J. The periimplant hard and soft tissues at different implant systems. A comparative study in the dog. Clin Oral Implants Res 1996 Sep;7(3):212-219.

4. Zarb GA, Albrektsson T. Consensus report: towards optimized treatment outcomes for dental implants. Int J Prosthodont 1998 Dec;80(6):641.

5. Gardner DM. Platform switching as a means to achieving implant esthetics. N Y State Dent J 2005 Apr;71(3):34-37.

6. Lazzara RJ, Porter SS. Platform switching: a new concept in implant dentistry for controlling postrestorative crestal bone levels. Int J Periodontics Restorative Dent 2006 Feb;26(1):9-17.

7. Prasad KD, Shetty M, Bansal N, Hegde C. Platform switching: an answer to crestal bone loss. J Dent Implants 2011 Feb;1(1):13-17.

8. Berglundh T, Lindhe J, Ericsson J, Mainello CP, Liljenberg B, Thomsen P. The soft tissue barrier at implants and teeth. Clin Oral Implant Res 1991 Apr-Jun;2(2):81-90. 
9. Jansen VK, Conrads G, Richter EJ. Microbial leakage and marginal fit of the implant abutment interface. Int J Oral Maxillofac Res 1992 Jul-Aug;12(4):527-540.

10. Cristalli MP, Marini R, La Monaca G, Sepe C, Tonoli F, AnnibaliS. Immediate loading of post-extractive single-tooth implants: a 1-year prospective study. Clin Oral Implants Res 2015 Sep;26(9):1070-1079.

11. Canullo L, Fedele GR, Iannello G, Jepsen S. Platform switching and marginal bone-level alterations: the results of a randomized-controlled trial. Clin Oral Implants Res 2010 Jan;21(1):115-121.

12. López-Marí L, Calvo-Guirado JL, Martín-Castellote B, GomezMoreno G, López-Marí M. Implant platform switching concept: an updated review. Med Oral Patol Oral Cir Bucal 2009 Sep;14(9):e450-e454.

13. Rodriguez AM, Rosenstiel SF. Esthetic considerations related to bone and soft tissue maintenance and development around dental implants: report of the Committee on Research in
Fixed Prosthodontics of the American Academy of Fixed Prosthodontics. J Prosthet Dent 2012 Oct;108(4):259-267.

14. Hsu YT, Lin GH, Wang HL. Effects of platform switching on peri-implant soft and hard tissue outcomes: a systematic review and meta-analysis. Int J Oral Maxillofac Implants 2017 Jan-Feb;32(1):e9-e24.

15. Ahmed KM, Elfatah SA, El-Mageed Katamish MA. Crestal bone loss of standard implant versus platform switch implant design using minimal invasive technique. Future Dent J 2016 Dec;2(2):74-79.

16. Hürzeler M, Fickl S, Zuhr O, Wachtel HC. Peri-implant bone level around implants with platform-switched abutments: preliminary data from a prospective study. J Oral Maxillofac Surg 2007 Jul;65(7 Suppl 1):33-39.

17. Cappiello M, Luongo R, Di Iorio D, Bugea C, Cocchetto R, Celletti R. Evaluation of peri-implant bone loss around platform switched implants. Int J Periodont Restorat Dent 2008 Aug;28(4):347-355. 